\title{
Aplikasi Sensor BH1750 untuk Sistem Monitoring Pertumbuhan Tanaman Cabai Menggunakan Arduino Bertenaga Surya Terintegrasi Internet of Things (IoT)
}

\author{
Syafrima Wahyu $^{(\mathrm{a})^{*}}$, Mohamad Syafaat ${ }^{(\mathrm{b})}$, Agnes Yuliana ${ }^{(\mathrm{c})}$ dan Revi \\ Meliyani $^{(\mathrm{d})}$ \\ Fakultas Sains dan Teknologi, Universitas Binawan, Jakarta, Indonesia, 13630 \\ Email : ${ }^{\left(a^{*}\right)}$ syafrima@binawan.ac.id, ${ }^{(b)}$ syafaat@binawan.ac.id, ${ }^{(c)}$ agnesyuliana@binawan.ac.id, \\ ${ }^{(d)}$ revi.meliyani@gmail.com
}

Diterima (15 Desember 2020), Direvisi (30 Januari 2021)

\begin{abstract}
The purpose of this study was to design a monitoring system for the maintenance of chili plant growth based on the Internet of Things (IoT) with a power source from solar panels. Important variables that support the growth of chilies are humidity, ambient temperature, proper watering time and duration, and the influence of light intensity. In our previous research, soil moisture, ambient temperature, watering time, and duration were measured. Therefore, in this study there are additional features for monitoring light intensity. Measurement of light intensity using the BH1750 sensor. The test was carried out in a room measuring $4 \times 3$ $m$ with a height of 2.5 meters. The lamp power used is 15 Watt. The measurement results at the most optimal sensor position are in a position of 90 degrees, namely the position of the sensor towards the light source. The highest value is 125.7 lux. Measurement results of all sensors on an Android-based application.
\end{abstract}

Keywords: Android, IoT, solar panel, sensor, monitoring system

\begin{abstract}
Abstrak. Tujuan dari penelitian ini adalah merancang sistem monitoring untuk mengamati pertumbuhan tanaman cabai berbasis Internet of Things (IoT) dengan sumber daya listrik berasal dari panel surya. Variable penting penunjang pertumbuhan tanaman cabai adalah kelembaban tanah, suhu lingkungan, waktu dan lama penyiraman yang tepat serta adanya pengaruh intensitas cahaya. Pada penelitian kami sebelumya, sudah dilakukan monitoring terhadap kelembaban tanah, suhu lingkungan serta waktu dan lama penyiraman. Oleh karena itu pada penelitian ini terdapat penambahan fitur monitoring pengukuran intensitas cahaya. Pengukuran intensitas cahaya menggunakan sensor BH1750. Pengujian dilakukan pada ruangan berukuran 4 x $3 \mathrm{~m}$ dengan tinggi 2,5 meter. Daya lampu yang digunakan yaitu sebesar 15 Watt. Hasil pengukuran didapatkan bahwa posisi sensor yang paling optimal adalah pada posisi $90^{\circ}$, yaitu posisi sensor mengarah ke sumber cahaya. Nilai pembacaan tertinggi adalah 125,7 lux. Hasil pengukuran dari semua sensor tersebut di tampilkan pada aplikasi berbasis android.
\end{abstract}

Kata kunci: Android, IoT, panel surya, sensor, sistem monitoring

\section{PENDAHULUAN}

Indonesia merupakan negara agraris yang sebagian besar mata pencarian penduduknya adalah petani. Salah satu tanaman yang merupakan komoditi pangan utama nasional [1] dan memiliki nilai ekonomis cukup tinggi dalam pertanian adalah tanaman cabai [2]. Seiring dengan bertambahnya penduduk, kebutuhan cabai di Indonesia pun semakin meningkat [3]. Pemenuhan kebutuhan yang semakin 
meningkat tersebut harus diiringi dengan peningkatan produktivitas pembudidayaan tanaman cabai. Pembudidayaan komoditas ini memiliki prospek yang dapat meningkatkan perekonomian, pengentasan kemiskinan, perluasan kesempatan kerja, pengurangan impor dan peningkatan ekspor non migas [4].

Produktivitas cabai saat ini cenderung fluktuatif disebabkan faktor iklim yaitu suhu dan kelembaban. Kelembaban tanah yang diperlukan tanaman cabai berkisar antara $50 \%$ sampai $70 \%$. Selain kelembaban tanah, suhu dan kelembaban lingkungan juga mempengaruhi pertumbuan tanaman cabai. Penurunan suhu yang tiba-tiba akan menghambat pertumbuhan buah [5]. Untuk nilai kelembaban yang diperlukan yaitu $\pm 80 \%$ [6]. Suhu dan kelembaban lingkungan sangat bervariatif dan terkadang tidak sesuai dengan syarat pertumbuhan ideal cabai merah. Parameter lainnya adalah berupa intensitas cahaya yang merupakan salah satu aspek yang mempengaruhi pertumbuhan tanaman [7]. Hal ini sejalan dengan penelitian yang dilakukan oleh Naomi tahun 2018 [8], yaitu tentang keefektifan spektrum cahaya terhadap pertumbuhan tanaman kacang hijau, menunjukkan bahwa terdapat spektrum warna yang paling efektif bagi pertumbuhan tanaman yaitu spektrum merah.

Salah satu permasalahan yang dialami oleh petani cabai adalah kesulitan memonitoring kelembaban tanah yang menjadi media tanam serta memonitoring suhu dan kelembaban ruang serta intensitas cahaya yang mempengaruhi pertumbuhan tanaman cabai. Monitoring pertumbuhan tanaman secara manual memiliki keterbatasan yang disebabkan berbagai aspek, antara lain: faktor fisik manusia meliputi kelelahan, subjektifitas, tidak kontinyu, ketidakseragaman dan ketidaktelitian. Metode ini sudah kurang optimal lagi untuk pengendalian yang memerlukan pengamatan secara kontinyu, dalam waktu yang panjang, dan memerlukan akurasi pengontrolan, serta produktifitas hasil yang tinggi [9].

Penerapan teknologi informasi Internet of Thing (IoT) memberikan alternatif solusi yang lebih baik untuk memonitoring pertumbuhan tanaman cabai [9]. Penggunaan sensor yang terintegrasi dengan Internet memungkinkan untuk monitoring dan pengontrolan jarak jauh. Penelitian mengenai pemanfaatan penerapan teknologi informasi dalam memonitoring pertumbuhan tanaman cabai sudah pernah dilakukan. Perancangan sistem monitoring suhun dan kelembaban tanaman cabai pada green house berbasis Labview sudah pernah dilakukan pada tahun 2016 [10].

Tahun 2018 sudah dibuat sistem monitoring parameter suhu cabe merah dengan sistem aeroponik pada greenhouse [11]. Penelitian sistem monitoring tanaman hortikultura pertanian di kabupaten indramayu berbasis internet of things sudah dilakukan pada tahun 2019 [12]. Tahun 2020 telah dibuat sistem monitoring dengan parameter suhu dan kelembaban lingkungan terintegrasi IoT bertenaga surya [13]. Penelitian yang sudah dilakukan terbatas pada monitoring terhadap parameter suhu dan kelembaban baik media tanam maupun lingkungan, namun informasi terhadap parameter intensitas cahaya yang diperoleh tanaman masih belum teridentifikasi. Dengan adanya informasi intensitas cahaya dan parameter lainnya tersebut akan sangat bermanfaat untuk dapat menentukan langkah atau penanganan terhadap budidaya cabai. Tujuan dari penelitian ini adalah untuk mengembangkan rancang sistem monitoring pertumbuhan tanaman cabai dengan melihat variabel intenitas cahaya yang diterima oleh tanaman cabai dengan memanfaatkan sel surya sebagai sumber daya listrik sistem. Dengan adanya transmisi data secara real time maka akan tercipta sebuah Bank Data (Data Base). 


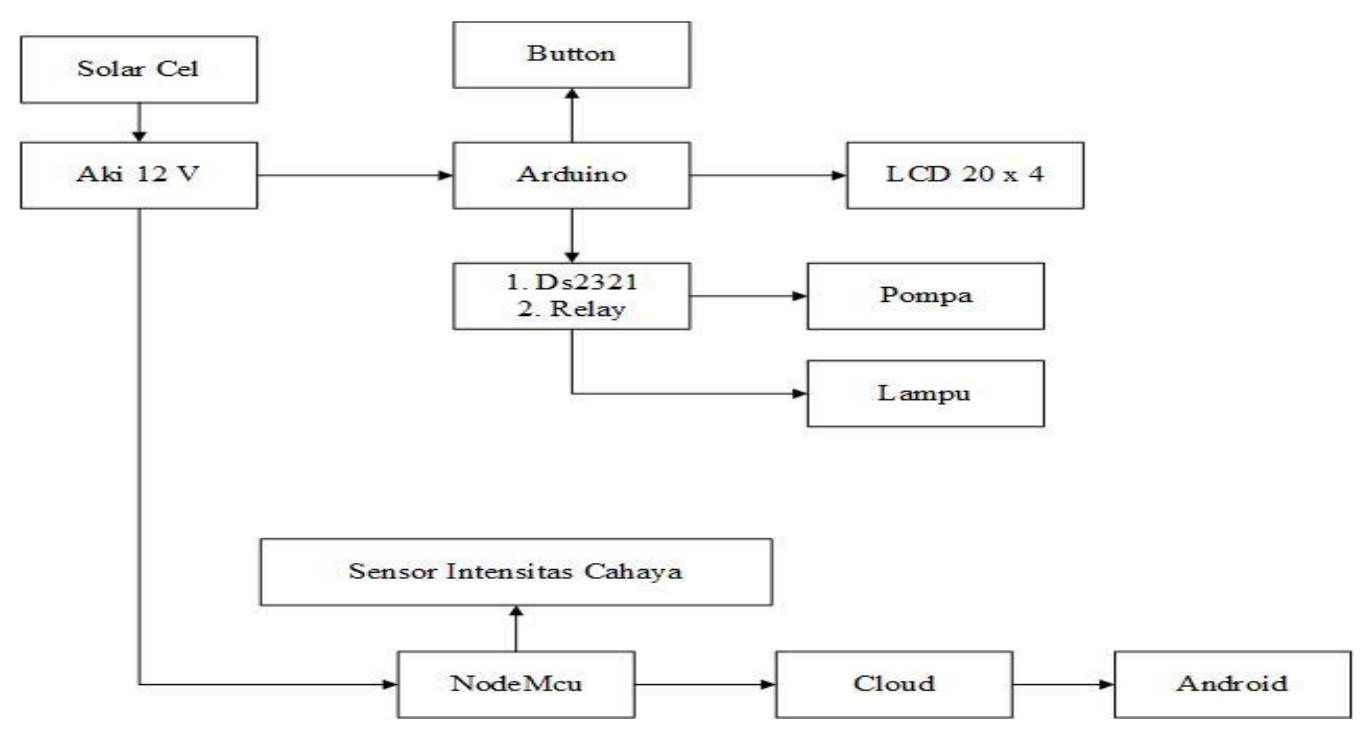

Gambar 1. Blok diagram

\section{METODE PENELITIAN}

Perancangan alat monitoring pertumbuhan tanaman cabai dilakukan dengan menggunakan metode eksperimen. Perancangan sistem ditunjukan pada Gambar 1. Penelitian ini dilakukan dalam beberapa tahapan, yaitu perancangan sistem, pembuatan alat dan pengujian subsistem dan sistem secara keseluruhan.

\section{Perancangan Sistem}

Secara garis besar sistem monitoring pertumbuhan tanaman cabai dapat dilihat pada Gambar 1. pada alat ini dilengkapi dengan sensor intensitas cahaya.

Pada Perancangan alat dan monitoring pertumbuhan tanaman cabai sebelumnya hanya terdapat data kelembapan tanah, suhu dan kelembapan udara dan tinggi tanaman [13]. Pada alat ini ditambahkan fitur pembaca intensitas cahaya. Sistem alat ukur intensitas cahaya terdiri dari rangkaian sensor yang berfungsi mengukur besarnya perubahan intensitas cahaya. Sensor yang digunakan untuk mengukur intensitas cahaya adalah sensor BH1750. Sensor untuk mengukur suhu adalah sensor DHT11, sedangkan untuk mengukur kelembaban tanah digunakan sensor YL-69 dan untuk mengukur ketinggian tanaman digunakan sensor ultrasonic HC-SR04. Komponen lain yang digunakan yaitu Arduino sebagai mikrokontroler dan menerima data dari sensor YL-69 kemudian mengirim data dari sensor ke NodeMCU ESP8266. NodeMCU sebagai serial komunikasi untuk menghubungkan sistem dengan aplikasi android dan Liquid Crystal Display (LCD) 20x4 sebagai penampil hasil pengukuran,

Prinsip kerja dari rangkaian sistem ini yaitu sensor DHT11 akan mendeteksi perubahan suhu yang terjadi di lingkungan, dan sensor YL-69 akan mendeteksi kadar air dalam tanah untuk menentukan tingkat kelembaban tanah dan sensor BH1750 untuk mengukur intensitas cahaya. Output dari sensor YL69 akan di terima oleh Arduino, kemudian melalui komunikasi Tx dan Rx, data dari Arduino akan di kirim ke NodeMCU. Sedangkan untuk output dari sensor DHT-11, sensor ultrasonic dan sensor cahaya akan langsung di terima oleh modul WiFi NodeMCU. Data dari modul WiFi NodeMCU kemudian akan di teruskan ke LCD melalui saluran SCL (Serial Clock) dan SDA (Serial Data). Modul WiFi NodeMCU 


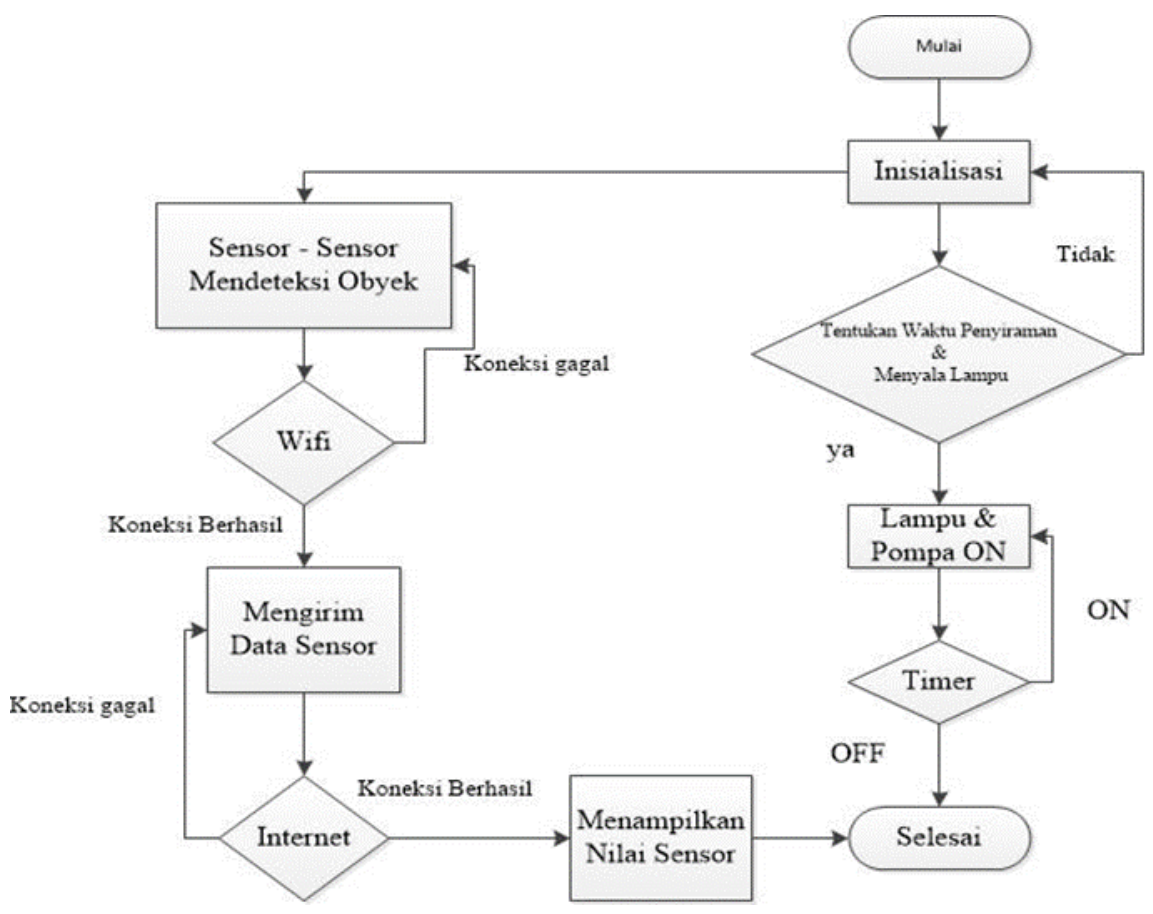

Gambar 2. Algoritma

akan menyimpan data, dan mengirim data dari sensor ke firebase. Smartphone android kemudian akan mengambil data dari firebase sehingga data hasil pengukuran dapat di tampilkan pada smartphone berbasis android.

Secara garis besar sistem monitoring dan penyiraman tanaman cabai dapat dilihat pada Gambar 2. Pada system ini ditempatkan beberapa sensor yaitu sensor kelembapan tanah, sensor suhu dan kelembapan, sensor ultrasonic dan sensor intensitas cahaya. Sensor tersebut akan dibaca oleh arduino sebagai parameter untuk melakukan penyiraman terhadap tanaman cabai kemudian data yang telah dibaca tersebut di upload ke API (Application Programming Interface) dengan menggunakan modul wifi NodeMCU. Kemudian data yang telah tersimpan di dalam API tersebut akan dibaca oleh smartphone android yang berfungsi untuk melakukan monitoring dan kontrol terhadap kondisi tanaman.

\section{HASIL DAN PEMBAHASAN}

Dalam menganalisa rancangan rangkaian peralatan sistem monitoring tanaman ini dilakukan dengan menguji sensor BH1750. Pengujian dilakukan sebagai berikut:

1. Pengujian sensor BH1750 terhadap besarnya daya lampu;

2. Pengujian sensor BH1750 terhadap jarak sumber cahaya;

3. Pengujian sensor BH1750 terhadap waktu pengukuran;

4. Pengujian sensor BH1750 terhadap luas ruangan;

5. Pengujian pembacaan sensor terhadap posisi sensor.

\section{Pengujian Terhadap Besarnya Daya Lampu}

Pengujian dilakukan pada ruangan berukuran $4 \times 3 \mathrm{~m}$ dengan tinggi $2,5 \mathrm{~m}$ dengan cara membedakan besarnya daya lampu. Daya lampu yang digunakan yaitu 5 
Watt, 10 Watt, 15 Watt, 20 Watt dan 25 Watt. Pengukuran dilakukan pada ruang tertutup dimalam hari. Hasil pengukuran terhadap besarnya daya lampu yang berbeda ditunjukan pada Tabel 1.

Dari hasil pengukuran tersebut di dapatkan bahwa besarnya daya lampu dapat mempengaruhi besarnya intensitas cahaya. Semakin besar daya lampu di suatu ruangan yang sama maka intensitas cahayanya pun akan semakin besar.

\section{Pengujian Sensor BH1750 Terhadap Waktu Pengukuran}

Pengujian dilakukan diruang terbuka (luar ruangan) dan didalam ruangan dengan waktu yang berbeda, yaitu pada pukul 08.00, $12.00,16.00$ dan 20.00. Hasil pengukuran intensitas cahaya terhadap waktu pengukuran yang berbeda ditunjukkan pada Tabel 2.

Dari hasil pengukuran tersebut didapatkan bahwa waktu pengukuran dapat berbengaruh terhadap besarnya intesitas cahaya. Hal itu dipengaruhi oleh adanya perubahan intensitas cahaya matahari.

\section{Pengujian Sensor BH1750 Terhadap Luas Ruangan}

Pengujian dilakukan terhadap luas ruangan yang berbeda beda. Luas ruangan yang digunakan yaitu ruangan $1,5 \times 1,5 \mathrm{~m}^{2}$, $2,5 \times 3 \mathrm{~m}^{2}, 3 \times 3 \mathrm{~m}^{2}$ dan $3 \times 4 \mathrm{~m}^{2}$. Pengukuran dilakukan dengan menggunakan daya lampu sebesar 15 watt. Hasil pengukuran intensitas cahaya terhadap luas ruangan.yang berbeda ditunjukkan pada Tabel 3..

Dari hasil pengukuran didapatkan bahwa luas suatu ruangan berpengaruh terhadap besarnya intensitas cahaya. Semakin luas suatu ruangan maka intensitas cahayanya akan semakin kecil. Luas ruangan berbanding terbalik dengan besarnya intensitas cahaya.

\section{Pengujian Pembacaan Sensor Terhadap Posisi Sensor}

Pengujian dilakukan dengan cara membedakan posisi sensor. Posisi yang digunakan yaitu sensor pada posisi $90^{\circ}, 180^{\circ}$ dan $270^{\circ}$. Pengujian ini dilakukan pada ruangan berukuran 4 × $3 \mathrm{~m}$ dengan tinggi 2,5 meter. Daya lampu yang digunakan yaitu sevesar 15 Watt. Hasil pengukuran intensitas cahaya terhadap posisi sensor yang berbeda ditunjukkan pada Tabel 4. Dari hasil pengukuran didapatkan bahwa posisi sensor yang paling optimal adalah $90^{\circ}$, Yaitu sensor mengarah ke sumber cahaya dengan nilai pembacaan tertinggi 125,7 lux.

Tabel 1. Hasil pengukuran terhadap daya lampu

\begin{tabular}{cc}
\hline Daya Lampu (Watt) & Pembacaan Sensor \\
\hline 5 & 20,9 lux \\
10 & 59,4 lux \\
15 & 125,7 lux \\
20 & 183 lux \\
25 & 244 lux \\
\hline
\end{tabular}

Tabel 2. Hasil pengukuran intensitas cahaya di ruang

\begin{tabular}{ccccc}
\hline Ruangan & $\begin{array}{c}\text { Jam } \\
08.00 \\
(\text { lux })\end{array}$ & $\begin{array}{c}\text { Jam } \\
\text { (lux) }\end{array}$ & $\begin{array}{c}\text { Jam } \\
\text { (lux) }\end{array}$ & $\begin{array}{c}\text { Jam } \\
\text { (lux) }\end{array}$ \\
\hline $\begin{array}{c}\text { Luar } \\
\text { Ruangan }\end{array}$ & 237,7 & 343 & 210 & 175,6 \\
$\begin{array}{c}\text { Dalam } \\
\text { Ruangan }\end{array}$ & 208,7 & 296,1 & 186 & 159,7 \\
\hline
\end{tabular}

Tabel 3. Hasil pengukuran intensitas cahaya terhadap luas ruangan

\begin{tabular}{cc}
\hline Luas Ruangan & Pembacaan Sensor \\
\hline $1,5 \mathrm{~m} \times 1,5 \mathrm{~m}$ & 202,5 lux \\
$2,5 \mathrm{~m} \times 3 \mathrm{~m}$ & 135,6 lux \\
$3 \mathrm{~m} \times 3 \mathrm{~m}$ & 130 lux \\
$3 \mathrm{~m} \times 4 \mathrm{~m}$ & $121,4 \mathrm{lux}$ \\
\hline
\end{tabular}


Syafrima Wahyu: Aplikasi Sensor BH1750 Untuk Sistem Monitoring Pertumbuhan Tanaman Cabai Menggunakan Arduino Bertenaga Surya Terintegrasi Internet of Things (IoT)

\section{Pengujian Pembacaan Sensor Terhadap Posisi Sensor}

Pengujian dilakukan dengan cara membedakan posisi sensor. Posisi yang digunakan yaitu sensor pada posisi $90^{\circ}, 180^{\circ}$ dan $270^{\circ}$. Pengujian ini dilakukan pada ruangan berukuran $4 \times 3 \mathrm{~m}$ dengan tinggi 2,5 meter. Daya lampu yang digunakan yaitu sevesar 15 Watt. Hasil pengukuran intensitas cahaya terhadap posisi sensor yang berbeda ditunjukkan pada Tabel 4.

Dari hasil pengukuran didapatkan bahwa posisi sensor yang paling optimal adalah $90^{\circ}$, Yaitu sensor mengarah ke sumber cahaya dengan nilai pembacaan tertinggi 125,7 lux.

\section{Panel Surya}

Dua panel surya 120WP monokristal yang dirangkai secara paralel dan dihubungkan ke Solar Charge Controller serta aki 12V/20Ah dan beban yang diuji. Hasil uji menunjukan tegangan rangkaian
Tabel 4. Hasil pengukuran intensitas cahaya terhadap posisi sensor

\begin{tabular}{cc}
\hline Posisi Sensor $\left(^{\circ}\right)$ & Pembacaan Sensor \\
\hline 0,180 & 122,9 lux \\
270 & 123,5 lux \\
90 & 125,7 lux \\
\hline
\end{tabular}

terbuka $18-22 \mathrm{~V}$ dan arus listrik rangkaian terbuka 1,5 A. Panel surya diarahkan menghadap utara (lokasi penelitian berada diselatan garis khatulistiwa) dan membentuk sudut $\pm 33^{\circ}$ terhadap bidang horizontal [13] . Hasil instalasi rancangan 3-Dimensi panel surya ditunjukkan pada Gambar 3.

\section{Tampilan Pada Aplikasi Android}

Untuk memudahkan monitoring pertumbuhan tanaman cabai, sistem dapat diakses melalui hp berbasis android. Tampilan pada aplikasi android dapat dilihat pada Gambar 4.

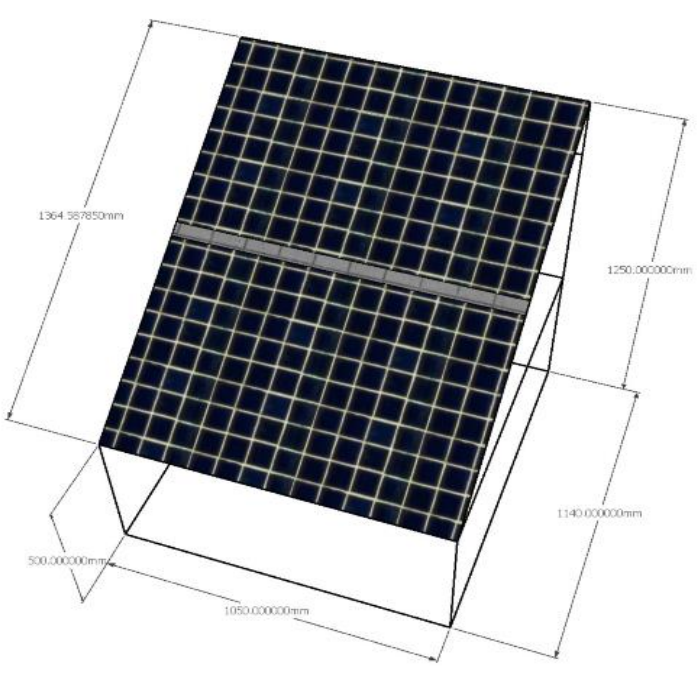

(a)

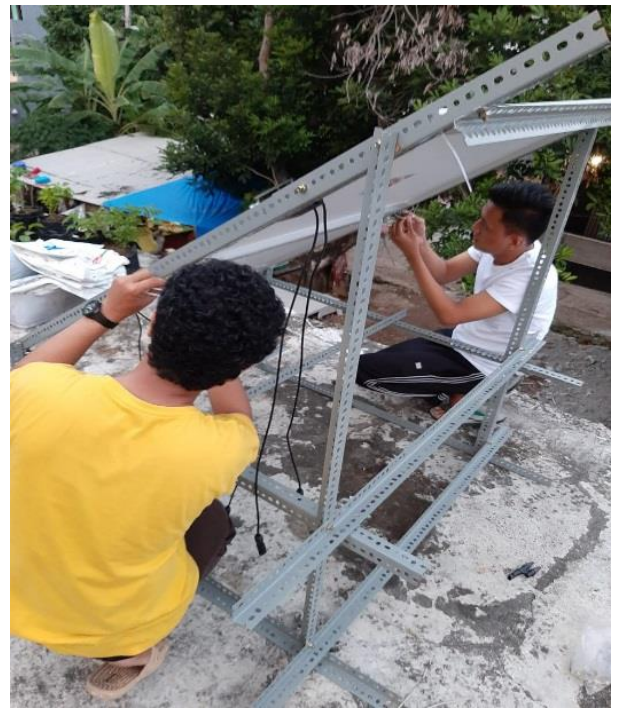

(b)

Gambar 3. (a) Rancangan 3 dimensi panel surya dan (b) Instalasi panel surya 

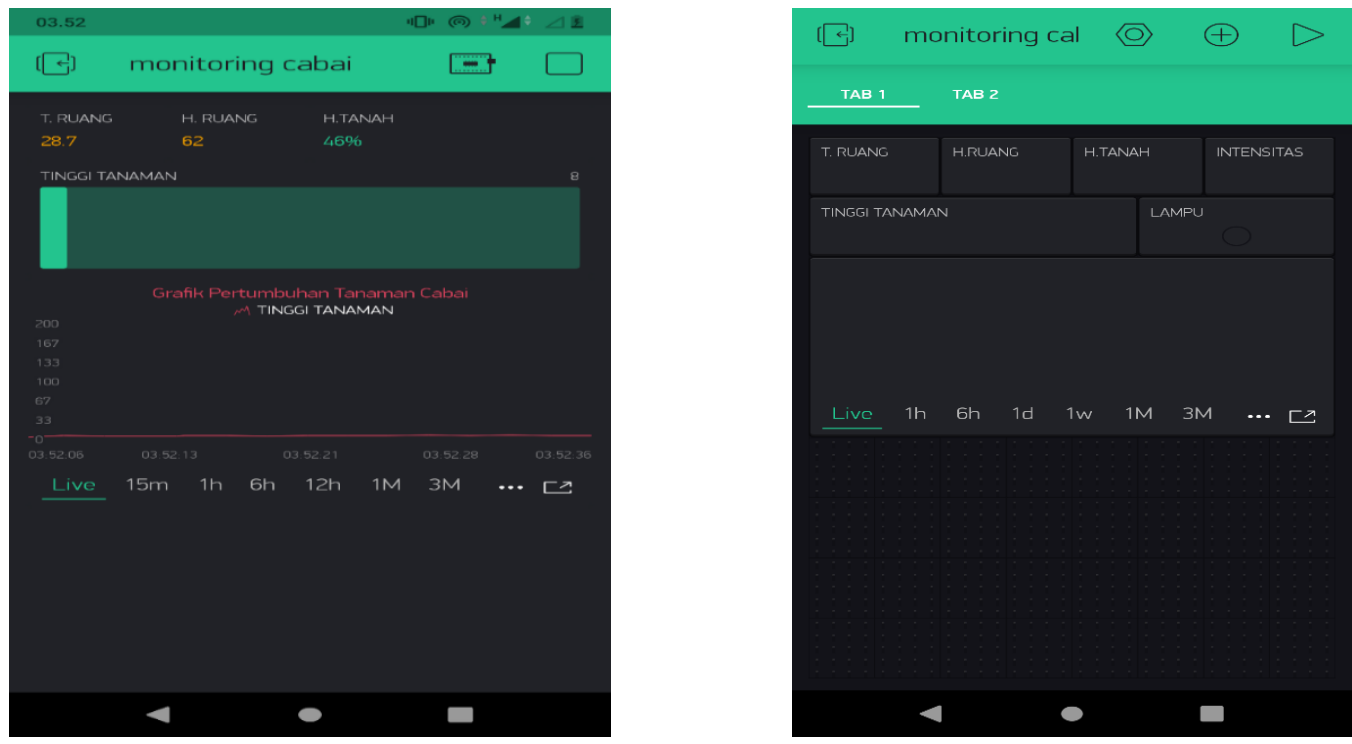

Gambar 4. Tampilan pada layar Handphone Android

\section{KESIMPULAN}

Penambahan fitur pengukuran intensitas cahaya Sistem monitoring pertumbuhan tanaman cabai berbasis IoT sudah berhasil dirancang. Pengukuran intensitas cahaya menggunakan sensor BH1750. Pengujian dilakukan pada ruangan berukuran 4 × $3 \mathrm{~m}$ dengan tinggi 2,5 meter. Daya lampu yang digunakan yaitu sebesar 15 Watt. Hasil pengukuran didapatkan bahwa posisi sensor yang paling optimal adalah pada posisi $90^{\circ}$, yaitu posisi sensor mengarah ke sumber cahaya. Nilai pembacaan tertinggi adalah 125,7 lux. Hasil pengukuran dari semua sensor tersebut di tampilkan pada aplikasi berbasis android. Sumber tenaga listrik sistem menitoring berasal dari panel surya yang mengarah ke utara dengan membentuk suduk $\pm 33^{\circ}$ terhadap bidang horizontal.

\section{UCAPAN TERIMAKASIH}

Penelitian ini merupakan salah satu luaran dari skema Penelitian Dosen Pemula (PDP) tahun anggaran 2020 KEMENRISTEK-BRIN. Penulis mengucapkan terimakasih kepada KEMENRISTEK-BRIN khususnya Deputi
Bidang Penguatan Riset dan Pengembangan atas dana hibah yang telah diberikan kepada kami sehingga penelitian ini dapat terealisasi dengan baik.

\section{DAFTAR PUSTAKA}

[1] A. N. A. Syah, T. Nuryawati, dan W. S. Litananda, "Pengembangan Smart Greenhouse untuk Budidaya Holtikultura", Semin. Nas. PERTETA 2018, no. 2010, pp. 1-10, 2018, [Online]. Available: http://www.ccw.ir/ content/ 92/default.aspx.

[2] G. Hapsoh, A. I. Amri, dan A. Diansyah, "Respons Pertumbuhan dan Produksi Tanaman Cabai Keriting (Capsicum Annuum L.) terhadap Aplikasi Pupuk Kompos dan Pupuk Anorganik di Polibag", J. Hortik. Indones., vol. 8, no. 3, p. 203, 2017, doi: 10.29244/jhi.8.3.203-208.

[3] C. Suherman, M. A. Soleh, A. Nuraini, dan A. N. Fatimah, "Pertumbuhan dan Hasil Tanaman Cabai (Capsicum sp.) yang Diberi Pupuk Hayati pada Pertanaman Kelapa Sawit (Elaeis Guineensis Jacq.) TBM I.," Kultivasi, 
vol. 17 , no. 2 , pp. $648-655,2018$, doi: 10.24198/kultivasi. v17i2.18116.

[4] S. M. Sholihah, L. S. Banu, A. Nuraini, dan P. A. Piguno, "Kajian Perbandingan Analisa Usaha Tani serta Produktivitas Tanaman Cabai Rawit di Dalam Polibag dan di Lahan Pekarangan", J. Ilm. Respati, vol. 11, no. 1, pp. 13-23, 2020.

[5] B. Samadi, Budidaya Cabai Merah Secara Komersial, Yogyakarta, Yayasan Pustaka Nusatama, 2007.

[6] C. Bambang, Cabai Dan Paprika Teknik Budidaya dan Analisis Usaha Tani, Kanisius, Yogyakarta, KANISIUS, 2007.

[7] Susilawati, Wardah, dan Irmasari, "Pengaruh Berbagai Intensitas Cahaya Terhadap Pertumbuhan Semai Cempaka (Michelia champaca L.) Di Persemaian," J. For. ISSN 1693 - 5179, vol. 14, no. 1, pp. 59-66, 2016.

[8] A. Naomi, J. Pertiwi, P. A. Permatasari, S. N. Dini, dan A. Saefullah, "Keefektifan Spektrum Cahaya Terhadap Pertumbuhan Tanaman Kacang Hijau (Vigna Radiata)", Gravity J. Ilm. Penelit. dan Pembelajaran Fis., vol. 4, no. 2, pp. 93-102, 2018, doi: 10.30870/gravity. v4i2.4036.

[9] L. Sutiarso, A. Suyantohadi, D. Kastono, dan A. P. Nugroho, "Aplikasi Sistem Monitoring Pertumbuhan
Tanaman Berbasis Web Menggunakan Machine Vision," Agritech, vol. 31, no. 4, pp. 359-367, 2011.

[10] S. Syarief, "Sistem Monitoring Suhu dan Kelembaban Tanaman Cabai pada Greenhouse Berbasis Labview", Jur. Tek. elektro, Politek. Negri Jakarta, vol. 15, no. 2, pp. 135-140, 2016.

[11] Alimuddin, D. M. Subrata, F. F. A, Nurmayulis, R. Arafiyah, dan Rida Oktarida, "Sistem Monitoring Parameter Suhu Cabe Merah Dengan Sistem Aeroponik pada Greenhouse untuk Mendukung Ketahanan Pangan Nasional", Flywheel J. Tek. Mesin Untirta, vol. IV, no. 2, pp. 91-95, 2018.

[12] A. Sumarudin, W. P. Putra, E. Ismantohadi, Supardi, dan M. Qomarrudin, "Sistem Monitoring Tanaman Hortikultura Pertanian Di Kabupaten Indramayu Berbasis Internet of Things (IoT)", J. Teknol. dan Inf. UNIKOM, vol. 9, no. 1, pp. 45-54, 2019.

[13] S. Wahyu, M. Syafaat, dan A. Yuliana, "Rancang Bangun Sistem Monitoring Pertumbuhan Tanaman Cabai Menggunakan Arduino Bertenaga Surya Terintegrasi Internet of Things (IoT)", J. Teknol., vol. 8, no. 1, pp. 2233, 2020, doi: https://doi.org/10.31479/ jtek.v1i8.63. 